\title{
DoCUMENTOS MUNICIPALES DE CEMENTERIOS. IDENTIFICACIÓN Y VALOR*
}

\author{
Norma Catalina Fenoglio**
}

\section{Resumen}

La identificación es el primer paso del tratamiento archivístico, indispensable para valorar las series. La valoración, etapa intelectual del proceso de evaluación, es fundamental para decidir el plazo de conservación de cada serie y asegurar la conformación del patrimonio documental. Dado que los municipios tienen a su cargo la gestión de los cementerios, en este trabajo se identifican los documentos que producen los municipios en relación con las defunciones y los cementerios y se estudian sus valores. Como estudio de caso, se analiza y compara la producción documental así como los procedimientos administrativos del área Cementerios de la Municipalidad de Morteros, en la provincia de Córdoba, Argentina, y la correspondiente al Ayuntamiento de Girona, en Cataluña, España.

Palabras clave: documentos de cementerio, identificación, valoración.

\begin{abstract}
Identification is the first step in the archival treatment, essential to appraise the series. The appraisal, intellectual stage of the evaluation process, is essential to decide the term of preservation of each series and to ensure the integration of documentary heritage. Municipalities are responsible for the management of cemeteries, so this work identifies the records that municipalities produce in relation
\end{abstract}

\footnotetext{
* Artículo elaborado sobre la base de la tesis para aprobación del V Master Propio Universitario en gestión documental y administración de archivos, presentado en la Universidad Internacional de Andalucía, España, en 2011.

** Escuela de Archivología, Universidad Nacional de Córdoba, Argentina. norma.cfenoglio@yahoo.com.ar
} 
with deceases and cemeteries, it also explores their archival values. As a case study, it analyzes and compares documentary production as well as the administrative procedures of the area Cemeteries of the Municipality of Morteros, in the province of Córdoba, Argentina, and the corresponding to the city of Girona, in Catalonia, Spain.

Keywords: cemetery documents, identification, values of the documents.

\section{Introducción}

La normativa sobre sepulcros, la arquitectura de los cementerios, los ritos y ceremonias religiosas que se desarrollan en torno a los difuntos, así como todos los elementos que integran la muerte, evidencian las particularidades y la idiosincrasia de cada pueblo.

Dado que los municipios tienen a su cargo la gestión de los cementerios, el objetivo de este trabajo es identificar y estudiar el valor de los documentos que ellos producen en relación con la muerte. Identificarlos, en primer lugar, para reconocer los documentos y las series a partir de las funciones, como proceso previo al de evaluación; valorarlos, seguidamente — como primera etapa del proceso de evaluación documental - para determinar sus valores - primarios y secundarios - y establecer el tiempo que deben conservarse.

Como estudio de caso, se analiza y se compara la producción documental, así como los procedimientos administrativos del área Cementerios de la $\mathrm{Mu}$ nicipalidad de Morteros, en la provincia de Córdoba, República Argentina ${ }^{1}$

1 Morteros está ubicada al noreste de la provincia de Córdoba, a $280 \mathrm{~km}$ de la capital provincial. Es una ciudad continental, situada en la llanura pampeana y su actividad económica es esencialmente agrícola ganadera. Fue creada por decreto provincial el 12 de agosto de 1891. Ocupa una superficie de $9,3 \mathrm{~km}^{2}$ y tiene alrededor de 20,000 habitantes, con una densidad de 2,150 personas por $\mathrm{km}^{2}$. La mayoría de la población desciende de los inmigrantes europeos fundamentalmente italianos del Piemonte-, que dieron origen al pueblo. Desde sus comienzos el municipio se ocupó de gestionar el cementerio, tanto en lo relacionado a las obras que la misma administración debía encarar (construcción de nichos, veredas y tapiales), como en lo concerniente a la venta de parcelas, obligaciones de los particulares (tamaño y profundidad de las fosas, características de los mausoleos), procedimiento para realizar las sepulturas (horarios, tipo de féretros), tarifas por los servicios y derechos para realizar construcciones, así como medidas relacionadas con la higiene pública. Actualmente la ciudad tiene dos cementerios: el San Salvador, que existe desde la creación de la localidad, con panteones, tumbas y nichos, 
y la correspondiente al Ayuntamiento de Girona, en la provincia homónima, de la comunidad autónoma de Cataluña, España. ${ }^{2}$ La elección de estos municipios no es casual. En Argentina se ha elegido a Morteros, por ser una ciudad cuya producción documental y de procedimientos conocemos, por haber trabajado el tema en diversas oportunidades, ${ }^{3}$ lo que permite considerarlo, en cuanto a su funcionamiento, como un municipio argentino medio. En España, se seleccionó Girona... como una posibilidad de estudio y cotejo, porque permite establecer analogías que llevan a comparar las similitudes y destacar las diferencias, por tratarse de una comparación de las denominadas lejanas, de diferente magnitud y contexto, pero similar significación.

Se trata de dos ciudades diferentes, tanto en antigüedad, como en tamaño y en situación geográfica, con procedimientos administrativos y tradiciones archivísticas propias, pero ambas tienen a su cargo la administración de sus cementerios. Conocer y cotejar los documentos que produce la función del cementerio, y cómo fueron evaluados en cada ciudad para su conservación, permitirá comprobar si funciones idénticas producen documentos iguales en cuanto a sus características y valores —aunque no tengan la misma de-

y un "cementerio parque", en el que los enterramientos se realizan en la tierra o en nichos. Ambos son de dominio público municipal. El municipio otorga en concesión temporaria el uso de parcelas, nichos o urnarios, previo cobro de la tasa correspondiente.

2 Girona está ubicada a $103 \mathrm{~km}$ de Barcelona. Tiene cerca de 97.000 pobladores en una superficie de $39.1 \mathrm{~km}^{2}$, con una densidad de 2480 habitantes por $\mathrm{km}^{2}$. Surgió hacia el $75 \mathrm{a}$. C., cuando los romanos fundaron Gerunda. Desde mediados del siglo XII habría existido en la ciudad un consejo municipal, de carácter consultivo, constituyendo una rudimentaria organización municipal. En 1284 el rey Pedro el Grande (II de Barcelona y III de Aragón) le concedió el régimen municipal autónomo. Después de sobrellevar las vicisitudes de todos los acontecimientos que soportó la corona catalana-aragonesa y, posteriormente España. En 1833 la ciudad fue declarada capital de la provincia que lleva su nombre y se consolidó como una ciudad industrial y de servicios. Hasta 1835 se enterró en los cementerios parroquiales, además de en los conventuales correspondientes. El cementerio general —actual Cementerio Municipal de Girona- comenzó a construirse en 1829 y a él fueron enviados los restos de los difuntos enterrados en las iglesias y cementerios de la ciudad. Hacia 1993, el ayuntamiento decidió construir otro, en el sureste de la ciudad, cercano al anterior, con capacidad para 20,000 sepulturas. En la actualidad, debido a la ampliación del ejido municipal de la ciudad, también dependen del Ayuntamiento de Girona otros tres cementerios: el de Santa Eugenia, el de San Daniel y el de Palau-Sacosta, que antiguamente pertenecían a municipios anexionados en 1963.

3 Ver Fenoglio, "Valor de los archivos de catastro"; Fenoglio, Evaluación de los documentos de las administraciones públicas municipales; Martínez de Sánchez, Álvarez Rodríguez y Fenoglio, "Entre memoria y olvido". 
nominación- o presentan diferencias, como consecuencia del procedimiento administrativo que les dio origen.

\section{El cementerio: concepción y ubicación en las ciudades}

De acuerdo con la época, las creencias, la situación económica, el nivel social y las costumbres de la sociedad, cada cementerio presenta características singulares, que se manifiestan fundamentalmente en la arquitectura, también en las representaciones simbólicas que se incorporan a ellos: esculturas, cruces y otros signos religiosos o no, como epitafios, fotografías y hasta en la vegetación que los rodea. Más allá de la necesidad de colocar en algún lugar el cuerpo de los difuntos, el cementerio es considerado lugar sagrado y espacio de memoria, porque en él "descansan los restos de las personas que vivieron, trabajaron y soñaron antes que nosotros". ${ }^{4}$

En Girona existió un cementerio romano y se enterró en las iglesias, especialmente en el interior de la catedral durante varios siglos, hasta que se construyó el primer cementerio público, en el siglo XIX.

Para las poblaciones que — como Morteros- surgieron como consecuencia de la inmigración de fines del siglo xIX y principios del siglo $\mathrm{xx}$, la legislación que regulaba la creación de pueblos y colonias hacía referencia concreta a la instalación del cementerio, ${ }^{5}$ por lo que éste nació junto con las edificaciones para la vivienda de sus habitantes.

En todos los casos, tanto la normativa general y específica, como los primeros contratos de posesión de espacios en las iglesias o de parcelas o nichos en los cementerios, fueron documentos de archivo identificados con la muerte cuyo valor permite hoy rehacer esos momentos tanáticos.

4 Gaido y Carranza, El cementerio de Villa Maria, p.13.

5 La Ley núm. 1412, sancionada el 16 de octubre de 1896 y promulgada el 23/10/96, en su artículo $11^{\circ}$, al determinar los requisitos a cumplimentar para fundar una colonia agrícola y villas, establecía: "Inmediatamente de aprobado el plano de una villa, extenderá el propietario escritura pública de donación al Gobierno de una extensión superficial de tres hectáreas: dos para edificios fiscales y una para cementerio, que se designarán previamente en el plano". 


\section{Administración de los cementerios}

La legislación española actual —que nos interesa para enmarcar el caso de Girona - aborda el tema de los cementerios desde dos puntos de vista: por un lado, el sanitario, a través de reglamentos de policía sanitaria mortuoria, y por el otro, el administrativo-fiscal, con normas dictadas por los municipios, las cuales se refieren a reglamentos de funcionamiento interno del cementerio, ordenanzas sobre cementerios y el régimen de tasas a aplicar por la prestación de determinados servicios. La Constitución española de 1931 estableció, por su parte, en su artículo 27: "los cementerios estarán sometidos exclusivamente a jurisdicción civil. No podrá haber en ellos separación de recintos por motivos religiosos". 6

En Argentina, tanto la administración como el ejercicio de poder de policía mortuoria corresponden a la órbita municipal. ${ }^{7}$ La Ley 1565 , del 25 de octubre de 1884, de creación del Registro del Estado Civil implicó un paso fundamental en el camino hacia la laicización del Estado, ya que a partir de entonces el registro de todos los hechos vitales - nacimientos, matrimonios y defunciones - fue responsabilidad de su órbita. Córdoba adhirió a esta Ley el 11 de octubre de 1889 y con ella se crearon las oficinas de Registro Civil en la provincia. ${ }^{8}$

La administración del cementerio por parte del municipio implica el cobro de tasas por la inhumación y exhumación de los cuerpos, así como la obligación de su mantenimiento y limpieza; pero comprende también el derecho real de propiedad sobre la tierra, y por ende, de las sepulturas construidas en ellos, así como la responsabilidad de todo lo que ocurre en su interior. Consecuentemente, el municipio es responsable de los cuerpos que se encuentran sepultados en cada fosa o sepulcro.

Respecto de las construcciones particulares en los cementerios, en el siglo pasado fue común que se vendieran los terrenos "a perpetuidad", lo

6 Valls i Rovira, La producció documental dels cementeris de Barcelona, p.38.

7 La Constitución Nacional (Art.5) establece que el tema corresponde a las provincias; la Constitución de la Provincia de Córdoba (Art.186), al igual que las de las demás provincias argentinas, dispone que es competencia material de los municipios. En concordancia, las sucesivas Leyes Orgánicas municipales, al fijar las funciones y materias que deben atender los municipios incluyeron taxativamente la atención de los cementerios.

8 Gaido y Carranza, El cementerio de Villa María, pp. 87-90. 
que permitió a las familias compradoras construir mausoleos, verdaderas obras de arte, algunos de los cuales han sido declarados parte integrante del patrimonio histórico-arquitectónico de las ciudades. Sin embargo, dado que el inmueble en el que están los cementerios forma parte del dominio público municipal con destino específico, las autoridades municipales no pueden transferir la propiedad a un particular, ya que de acuerdo a la doctrina jurídica del derecho de propiedad, esta implica el ius utenti (derecho de uso), el ius fruendi (derecho de goce) y el ius abutendi (derecho de disposición) sobre el bien, y el comprador en ningún caso puede destinar el terreno adquirido a otra cosa que no sea el enterramiento de personas. De ello se desprende que los particulares solo tienen un derecho real administrativo sobre el sepulcro que adquieren. ${ }^{?}$

Por distintas razones, que van desde lo demográfico - insuficiencia de espacio en los cementerios públicos- a lo social —interés de ciertos estratos sociales en tener enterratorios con determinadas condiciones de servicio- pasando por lo cultural — tendencia a mantener tradiciones religiosas - y lo meramente económico — prestación de un servicio a través de la iniciativa privada con contralor de la autoridad pública- en el siglo xx comenzó la construcción de cementerios privados. En este caso, la propiedad del inmueble y la administración está a cargo de particulares, pero el municipio regula y controla su uso y funcionamiento. ${ }^{10}$

\section{Documentos de cementerios en los municipios}

Como estudio de caso, se analizan los documentos que produce la Municipalidad de Morteros, atento a las funciones y competencias que posee en materia de cementerios. Cuando sea pertinente, se lo comparará con los del Ayuntamiento de Girona. Cabe aclarar que se identificarán solo las series relacionadas directamente con su gestión y con los servicios fúnebres, es decir, no se tendrán en cuenta las referidas a cementerios en forma indirecta, como pueden ser, por ejemplo, los legajos del personal, los

\footnotetext{
$9 \mathrm{El}$ tema de la relación entre el Estado municipal y los particulares y las relaciones jurídicas que implican las sepulturas en Argentina puede verse en Solari, Echenique y Gruttadauría, “Cementerios públicos. Legislación nacional”, pp. 197-215.

10 Solari, Echenique y Di Pasquantonio, "Cementerios privados”, p. 218.
} 
libros de inventario de bienes o los expedientes de contratación de servicios de mantenimiento de espacios comunes (limpieza, forestación y similares), que forman parte de series que no se refieren específicamente al tema que nos ocupa.

\section{Reglamento de Cementerio}

A nivel municipal, en Argentina como en España, el documento básico que regula el funcionamiento de los cementerios es la "Ordenanza general de cementerios”. Según Ángela Vinti, Teresita Solari y otros, estas ordenanzas son similares en todo el país, regulan el régimen administrativo de los enterramientos, establecen las competencias municipales en la materia, así como disposiciones para la inhumación, exhumación, cremación y traslado de cadáveres; fijan el régimen de concesiones sepulcrales, disponen todo lo atinente a la urbanización de los cementerios y precisan las tasas y cánones a que dan lugar los servicios. ${ }^{11}$ Esas ordenanzas generalmente no mencionan qué documentos deben producirse y de los generados, no especifican su tratamiento posterior.

En la Municipalidad de Morteros, en la primera ordenanza que se conoce sobre el cementerio, el artículo $11^{\circ}$ menciona la necesidad de llevar, además del "talonario de administración, un libro cronológico en el que se anotarán las partidas de defunción”. ${ }^{12}$ La ordenanza de 1952, que sustituyó a la anterior, determinó la obligatoriedad de llevar "libros y registros para anotación cronológica de las defunciones que se produzcan, como de las inhumaciones que se hagan en las distintas secciones del cementerio, de acuerdo al plano oficial aprobado". ${ }^{13}$

En España, la existencia de disposiciones legales para regular el servicio del cementerio se remonta a finales del siglo XVIII, durante el reinado de Carlos III. Las más antiguas son el "Reglamento del cementerio del real sitio de San Ildefonso", ${ }^{14}$ del 9 de febrero de 1785, y la "Real cédula" del 3 de

11 Vinti, Solari, Romero y otros: "Sepelios y sepulcros en la Provincia de Córdoba", p. 364.

12 AGM, Libro de Ordenanzas 1929-1940, fos. 35-37: Ordenanza núm. 35.

13 Ibid., 1952, fos. 18 a 21, Ordenanza núm. 7, Art.17².

14 San Ildefonso o La Granja, es una población situada a $11 \mathrm{~km}$ de la ciudad de Segovia y $54 \mathrm{~km}$ al noroeste de Madrid. La zona fue coto de caza y residencia de verano de los reyes de España. Felipe V hizo construir un palacio, que fue embellecido por Carlos III quien, 
abril de 1787, que fijó reglas de comportamiento respecto de los muertos para todo el reino. A partir de esta "Real cédula", se fueron dictando disposiciones acerca de la construcción de cementerios, los derechos de enterramientos, las inhumaciones, exhumaciones y traslados de cadáveres, la responsabilidad de los ayuntamientos en la administración, cuidado y mantenimiento de los cementerios, mediante diversos instrumentos: Reales órdenes, Reales decretos, Leyes. ${ }^{15}$

En cuanto a legislación general actual, el "Reglamento de policía sanitaria mortuoria" del 22 de diciembre de 1960 legisla sobre todos los aspectos relativos a inhumaciones de cadáveres, traslados y reinhumaciones dentro de España y desde y hacia el exterior, así como lo concerniente a construcción, reforma, ampliación y división de cementerios, construcción de sepulcros, empresas fúnebres, féretros y vehículos para el transporte de muertos, mientras que el reglamento del 20 de julio de 1974 incorporó conceptos relativos a las cremaciones. En Catalunya, el "Reglamento de policía sanitaria mortuoria" de la Generalitat (gobierno autónomo de Cataluña) vigente, data de 1997. Cada ayuntamiento, por su parte, dicta su propio reglamento, en los que se tiene en cuenta la legislación del Estado y autonómica, y se desarrollan los aspectos particulares, en especial los relacionados con el funcionamiento interno de cada cementerio, los procedimientos administrativos que regulan el derecho funerario, así como las tipologías documentales obligatorias. ${ }^{16}$

Con respecto a los documentos a producir, el "Reglamento de cementerios municipales del Ayuntamiento de Girona" establece: "En las dependencias municipales del ayuntamiento se tendrá el registro público

\footnotetext{
además, reordenó el casco urbano, lo delimitó con una muralla e hizo construir un cementerio extramuros, siendo la primera población de España en la que los enterramientos dejan de realizarse en las iglesias. El Reglamento fue redactado con acuerdo del ordinario eclesiástico y establecía que todos los cadáveres, de cualquier estado y dignidad, debían ser enterrados en el cementerio construido extramuros. Ver Cardona Saldarriaga y Sierra Varela, "Salud pública y prohibición de enterramientos en las iglesias en la Nueva Granada a finales del siglo XVIII", pp. 54-72; Nistal, Legislación funeraria y cementerial española, pp. 29-53 y Brel Cachón, "La construcción de cementerios y la Salud Pública a lo largo del siglo XIX", pp.155-196.

15 Un listado de "Disposiciones Legales sobre la construcción de cementerios" se encuentra como apéndice II en el artículo de Brel Cachón, citado.

16 Valls i Rovira, La producció documental dels cementeris de Barcelona, pp. 47-49.
} 
de todas las sepulturas y de las actuaciones que se realicen, un libro de reclamaciones y los obligatorios que marque la legislación vigente". ${ }^{17}$ Dado que el servicio está concesionado, este registro está a cargo de la empresa que lo administra.

Desde el punto de vista archivístico, y específicamente del análisis documental, para dictar estas medidas las autoridades correspondientes han utilizado y utilizan en todos los casos, documentos dispositivos, ${ }^{18}$ los que constituyen series con valor secundario predecible o evidencial y por lo tanto, son de conservación permanente.

\section{Principales series}

Clasificadas según su función, en Morteros se producen las siguientes series documentales relacionadas con los cementerios:

1. En relación con el patrimonio municipal

a) Expedientes de construcciones de particulares en cementerios.

b) Expedientes de concesión de uso de parcelas.

c) Constancia de arrendamiento de fosa y/o nicho.

d) Fichas catastrales.

e) Expediente o legajo de adquisición del inmueble.

f) Legajo de obras en los cementerios.

2. En relación con los servicios fúnebres

a) Autorizaciones de inhumación.

b) Autorizaciones de exhumación para traslado.

c) Autorizaciones de exhumación para incineración.

d) Autorizaciones de exhumación para reducción.

e) Registro de inhumaciones.

17 Reglament dels cementiris municipals. Aprobado el 10/10/95, publicado en el BOP núm. 150 del 11/11/95, Art. $8^{\circ}$, en http://www.girona.cat/ajuntament/ordenances/sanitat/cementiris. html [consulta 24 de febrero de 2011].

18 El documento dispositivo se define como aquel en el que se registra la voluntad de una autoridad, con la finalidad de ser obedecida. 
3. En relación con la renta municipal

a) Registro de propietarios de sepulturas.

b) Registro de pagos y deudores.

Se analizan, a continuación, cada una de las series, comparándolas con series similares en Girona.

\subsection{En relación con el patrimonio municipal}

\section{1. a) Expediente de construcciones de particulares en cementerios}

Es un documento compuesto que se origina a solicitud de la persona o entidad titular del derecho de propiedad de un predio y en el que constan los antecedentes relacionados con toda obra nueva, reparación o reforma de sepulturas. Contiene solicitud del titular, planos del proyecto y de ubicación de la obra; nombre del profesional actuante, informe técnico del área Obras Privadas, permiso de construcción otorgado, comprobante del pago de la tasa correspondiente, certificado de final de obra. Se conservan en forma permanente porque contienen información que trasciende la obra en sí, ya que permiten conocer a quienes se otorgaron concesiones, si fue a familias o a instituciones, los nombres de los profesionales que actuaron en el lugar, el estilo arquitectónico imperante en un momento específico, la situación socioeconómica de una familia determinada y hasta la ideología del profesional y de los propietarios así como su visión de la muerte.

Si se trata de una reparación menor, pintura o revoque, los requisitos son menores y el expediente se elimina a los cinco años.

En el Ayuntamiento de Girona se produce la serie de "Expedientes de permisos de obras e instalaciones de elementos ornamentales en las sepulturas", con características similares al expediente que se está tratando. Es un documento compuesto cuya función administrativa es valorar técnicamente y otorgar permiso al titular de un panteón o de una capilla de esquina, para realizar obras menores, tales como cambios en fachada, reparaciones, reformas, trabajos en los jardines, colocación de elementos decorativos y similares, así como liquidar las tasas correspondientes. El expediente incluye: solicitud, planos y/o diseños, informe técnico y liquidación. La "Taula d'avaluació documental” de Cataluña dispone que es una serie de conservación permanente, por criterios similares a los de 
Morteros, excepto los que se refieren a nichos (cambios de lápidas), que se eliminan totalmente al término de dos años. ${ }^{19}$

\section{1. b) Expedientes de concesión de uso de parcelas}

La municipalidad de Morteros no vende los espacios, sino que los otorga en concesión temporaria. La ordenanza establece que se otorgarán por decreto fundado del Departamento Ejecutivo ${ }^{20}$ pero no fija el procedimiento a seguir. En la del área Cementerio, dictamen de asesoría jurídica, decreto de otorgamiento y práctica, se inicia con el pedido del interesado e incluye informe técnico y de factibilidad notificación correspondiente. Estos expedientes se conservan en forma permanente.

En Girona, el otorgamiento de las concesiones está regulado en el "Reglamento de cementerios" y se realizan por convocatoria pública. Da origen a un expediente muy interesante, cuya serie se denomina "Expedientes de gestión de derechos funerarios sobre sepulturas", que incluye solicitud, informe técnico, resolución con liquidación de tasa y notificación con otorgamiento de un título en el cual se anotan todas las inhumaciones y exhumaciones y fecha en que se realizan. Las renovaciones, retrocesiones, cambios de titularidad y servicio de duplicado de títulos son trámites entre particulares. ${ }^{21}$ Concluido el valor administrativo y legal, estos expedientes se eliminan en forma total a los cuatro años de su finalización, ya que la misma información se anota en el libro "Registro General de sepulturas y parcelas" —al que se hará referencia en el punto 2.1.-d)—, que se conserva en forma permanente. ${ }^{22}$

19 “Taula d'avaluació documental”. Codi: 432 DOGC: 3604 Sèrie documental: Expedients de permisos d'obres i instal•lacions d'elements ornamentals a les sepultures, en http://cultura. gencat.cat/arxius/cnatdt/docs/432.doc. [Consulta 20 de febrero de 2011].

20 Ordenanza general de cementerios núm. 1860, sancionada el 22/04/2003 y publicada en el Boletín Municipal núm. 90, del 30/04/2003, $3^{\text {a }}$ parte: Concesión de Uso de Parcelas en los Cementerios, Art.30 a 35.

21 Las concesiones de derecho funerario y las renovaciones se pueden otorgar a corto o largo plazo, según el tipo de sepultura y según se trate de un cementerio u otro. Así, el uso de hipogeos, esquinas o ángulos y tumbas se otorga por 50 años y el de nichos y columbarios, por 25 años, mientras que las concesiones temporales a corto plazo tienen una duración de cinco años en el cementerio nuevo y de dos años en el resto de cementerios municipales (Reglament dels cementiris municipals. Aprobado el 10/10/95, publicado en el BOP núm. 150 del 11/11/95, Art. $20^{\circ}$, en http://www.girona.cat/ajuntament/ordenances/sanitat/cementiris. html [consulta 24 de febrero de 2011]

22 "Taula d'avaluació documental". Codi: 434 DOGC: 3604 Sèrie documental: Llibre registre 


\section{1. c) Constancia de arrendamiento de fosas $y / 0$ de nichos}

En Morteros, los nichos y las fosas se otorgan en arrendamiento. ${ }^{23}$ Este hecho genera un contrato - que denominan "constancia" - en el que se consigna: fecha, nombre, apellido y domicilio del arrendatario solicitante, ubicación catastral del nicho o fosa en cuestión, datos identificatorios del cadáver, número de acta de defunción, fecha de fallecimiento y de caducidad de la inhumación, monto y fecha del pago del arriendo por año y obligaciones que asume el arrendatario. Este documento, firmado por el arrendatario y por el responsable del municipio, sirve al ciudadano como prueba de la posesión y a la administración para identificar al responsable y el plazo de la concesión. El arrendatario debe abonar un derecho anual, que se fija en la "Ordenanza tributaria" correspondiente. La información que contienen estas constancias se transfiere a una base de datos que permite ubicar rápidamente al responsable de una parcela o la ubicación de una sepultura. Este instrumento de búsqueda es un documento activo que se actualiza a medida que se producen modificaciones.

Concluido su valor administrativo, las constancias siguen siendo valiosas, ya que en muchos casos es el único documento que prueba dónde está o estuvo enterrado un cuerpo. Se conservan en forma permanente, y son ordenadas catastralmente.

En el ayuntamiento de Girona, los nichos se otorgan en concesión de carácter administrativa, por un término de 25 años renovables por igual plazo y el adquirente debe abonar el derecho cuyo monto se fija en la "Ordenanza fiscal". ${ }^{24}$ El trámite se realiza mediante el "Expediente de gestión de derechos funerarios sobre sepulturas", explicado en el punto 2.1.-b) y una copia del título otorgado se conserva en el mismo expediente, por lo que no constituyen serie.

general de sepultures i parcel•les, en http://cultura.gencat.cat/arxius/cnatdt/docs/434. doc. y Codi: 438 DOGC: 3604 Sèrie documental: Llibre registre de concessions temporals de sepultures, en http://cultura.gencat.cat/arxius/cnatdt/docs/438.doc. [Consulta 20 de febrero de 2011]

23 El plazo de la concesión de uso es de 25 años, renovable por cinco años más.

24 Reglament dels cementiris municipals. Aprobado el 10/10/95, publicado en el BOP núm. 150 del $11 / 11 / 95$, Art. $19^{\circ}$ y $20^{\circ}$, en http://www.girona.cat/ajuntament/ordenances/sanitat/ cementiris.html [Consulta 24 de febrero de 2011] 


\section{1. d) Fichas catastrales}

Son fichas en cartulina, ordenadas topográficamente, que se encuentran en la oficina administrativa del cementerio en Morteros. Permiten identificar cada parcela y los cadáveres enterrados en cada una de ellas; incluyen información sobre signatura catastral, superficie, nombre y apellido del responsable, breve descripción de la construcción, datos de las personas sepultadas (fecha de inhumación, nombre y apellido), observaciones (cambio de propietario, modificaciones de estructura, etc.) A ellas se les anexan las autorizaciones de inhumaciones, traslados, exhumaciones o reducciones que correspondan a la parcela. Estas fichas tienen vigencia mientras exista el panteón y haya cadáveres depositados en él. Tienen valor informativo e histórico, ya que permiten conocer lo que ocurrió en la parcela a lo largo del tiempo. La misma información se carga en una base de datos; pero de igual modo, las fichas se conservan en forma permanente en el cementerio.

El documento equivalente en el Ayuntamiento de Girona es el libro Registro General de Sepulturas y parcelas, conocido como "Registro de nichos", en el que se asientan, desde 1829, todos los movimientos que se realizan en cada sepultura (inhumaciones, exhumaciones, transmisión de derechos funerarios, obras realizadas, etcétera). Se trata en consecuencia, de un documento recapitulativo de la información existente en los expedientes de gestión de derechos de sepultura, de incineración de cadáveres, de autorización de enterramiento de cadáveres, de exhumación de cadáveres por traslado de sepultura y de desalojo de sepulturas, tanto las alquiladas como las cedidas en propiedad. La serie se conserva en forma permanente en el ayuntamiento. ${ }^{25}$

\section{1. e) Expediente o legajo de adquisición de inmueble}

Es un documento compuesto en el que se conservan todos los antecedentes relacionados con la compra de un terreno para construir o ampliar los cementerios públicos: copia de la ordenanza de autorización de compra; copia de la ordenanza de declaración de interés público del

25 “Taula d'avaluació documental”. Codi: 434 DOGC: 3604 Sèrie documental: Libre registre general de sepultures i parcelles, en http://cultura.gencat.cat/arxius/cnatdt/docs/434.doc. [Consulta 20 de febrero de 2011]. 
terreno, si corresponde; propuestas, boleto de compra-venta, copia de la escritura traslativa de dominio y todo otro documento que la operación hubiera producido. Es un documento de mucho valor, dado que son las pruebas del dominio adquirido por el municipio con un fin específico, y es de conservación permanente. No se lo conserva como "documento de cementerio", sino en la serie que incluye todas las adquisiciones municipales con destino a uso público. Lo mismo ocurre en el Ayuntamiento de Girona, donde existe en la unidad de patrimonio.

\section{1. f) Legajos de obras municipales en los cementerios}

Cada obra (capilla, osario, cuerpo de nichos, veredas, etc.) que realiza el municipio en los cementerios públicos, da origen a un documento compuesto, en el que se encuentran todos los antecedentes de la obra en cuestión: memoria, planos y presupuesto del proyecto, llamado a licitación o a concurso (de acuerdo con el monto del proyecto), presentaciones de los oferentes, acta de apertura de las ofertas, contrato de obra, certificado de aprobación de los trabajos y todo otro documento que se haya producido en el transcurso de la construcción. Este documento está vigente hasta que terminen todos los derechos y obligaciones generados por la obra realizada, tanto del municipio (garantía de los trabajos) como del ejecutor de la obra (cumplimiento del pago). Se conservan en el Archivo Administrativo del área Obras Públicas del municipio durante diez años contados a partir del término de vigencia, se depuran para conservar solo la propuesta ganadora y los documentos con valor secundario y se transfieren al Archivo General. Cuando se trata de trabajos menores (veredas, por ejemplo), se eliminan totalmente.

En el Ayuntamiento de Girona, la serie equivalente es "Construcción y mantenimiento de equipamientos municipales", que no se analiza por entenderse que se relaciona en forma indirecta con el tema.

\subsection{En relación con los servicios fúnebres}

\section{2. a) Autorizaciones de inbumación}

En Argentina, el "Registro nacional de la personas" establece que para inhumar a una persona fallecida en un cementerio determinado debe presentarse copia del Acta de defunción y la autorización de inhumación 
emitida por la autoridad correspondiente. Si el muerto proviene de otra localidad, la oficina del Registro Civil transcribe el Acta de defunción con la aclaración "trascripción por traslado".

La autorización de inhumación es un documento que se confecciona en dos ejemplares; contiene fecha, identificación del cadáver, lugar y fecha de fallecimiento, número del Acta de defunción, cementerio y sepulcro de destino y firma del responsable de la oficina. El original debe ser entregado al responsable del cementerio quien lo adjunta a la "Ficha catastral". En el Archivo de Oficina se conserva el segundo ejemplar, ordenado cronológicamente, durante cinco años.

En el ayuntamiento de Girona se producen "Expedientes de inhumación o incineración de cadáveres", que incluyen la solicitud correspondiente, además de título de la sepultura, certificado de defunción, licencia de enterramiento otorgado por el Registro Civil, autorización de inhumación, si el cadáver no es el titular de la sepultura, orden de inhumación o de incineración de la brigada del cementerio, resolución judicial (en caso de que el cadáver provenga de una intervención judicial) y liquidación de las tasas. En algunos casos, dado que la gestión de los cementerios está concesionada, el expediente también incluye los documentos relacionados con los servicios funerarios contratados. Como la información que contienen estos expedientes existe también en otros documentos recapitulativos de conservación permanente (libro Registro unificado de inbumaciones, exhumaciones e incineraciones y libro Registro general de sepulturas y parcelas) y no tienen ningún valor determinado, la "Tabla de evaluación documental"propone la eliminación a los cuatro años de la finalización del expediente, siempre que los datos estén transcritos en los registros correspondientes. ${ }^{26}$

26 Esta serie fue reevaluada en marzo de 2011 y agrupa a las anteriores numeradas como Codi: 427 y 430. En el Registro Civil se conserva también copia de la licencia de enterramiento. (Información remitida vía electrónica por Lluís-Esteve Casellas i Serra). 


\section{2. b), c) y d) Autorizaciones de exhumación para traslado / para incineración /}

para reducción ${ }^{27}$

Para trasladar un féretro - incluso dentro del mismo cementerio-, para exhumar, incinerar o para reducir un cadáver, se requiere de un documento que lo autorice. Esto es así para evitar el tráfico de cadáveres y porque la municipalidad es responsable de los cuerpos sepultados en su jurisdicción.

El trámite inicia con la solicitud del familiar o interesado en realizar el traslado, la incineración o la reducción, que tiene carácter de declaración jurada. En ella, además de los datos de identificación y su relación con el fallecido, se asientan las referencias sobre el cadáver que se quiere trasladar, incinerar o reducir, el lugar en que se encuentra y los motivos que justifican el pedido. El responsable de la oficina emite una autorización, similar - en formato y en contenido informativo- a la de inhumación de cadáveres, también en dos ejemplares. En la parte superior del formulario consta el motivo de la exhumación: "traslado interno" (a otra sepultura dentro del mismo cementerio o de uno a otro de los cementerios de la ciudad) o "traslado externo" (a otra localidad o para ser reducido o incinerado). El original se entrega en el cementerio y, una vez concretada la exhumación, el responsable del cementerio certifica y firma - al dorso de la misma autorización - lo realizado. Conserva las autorizaciones en forma permanente, ordenadas cronológicamente. Si se trata de un traslado interno, en la municipalidad se otorga también una autorización de inhumación para darle ingreso, la que se adhiere a la "Ficha catastral" correspondiente a la parcela de destino. La solicitud se conserva en el Archivo Administrativo junto a la copia de la autorización entregada y se elimina a los cinco años.

Una situación especial es el traslado de un cadáver que aún no ha sido inhumado, es decir, cuando la persona fallecida en Morteros es sepultada en otra ciudad. En este caso el documento que se otorga es un "Permiso de traslado", que vale también como autorización de libre tránsito del cadáver en la ruta. Contiene, además de los datos del muerto, lugar y fecha de

27 Estas series se analizan agrupadas porque comparten el formato aunque contienen diferente información según el hecho que testifican y el fin de la exhumación: traslado, incineración o reducción. 
defunción y lugar de destino, el nombre de la empresa fúnebre que realiza el traslado y la firma del responsable municipal que autoriza la acción.

En Girona también se producen "Autorizaciones para traslado de cadáveres, entre cementerios", las que, a menudo, se incluyen en los "Expedientes de gestión de derechos funerarios sobre sepulturas".

Por otra parte, la serie "Expedientes de autorización de exhumación de cadáveres por traslado de sepultura o incineración sin la presencia de la familia" contiene la autorización correspondiente y dado que la información existe en varios documentos recapitulativos (libro Registro General de Sepulturas y Parcelas; libro Registro de exbumaciones y traslado de cadáveres y/o libro Registro de Incineraciones de cadáveres) se los elimina al cabo de cinco años. ${ }^{28}$

\section{2. e) Registro de inbumaciones}

En Morteros se lo llama también "Registro de enterramientos". Se trata de libros de gran formato en los que, como lo indicaba el reglamento de 1952, se asentaban en forma cronológica los cadáveres que ingresaban para ser inhumados. Contenían datos sobre la identidad del occiso - nombre, sexo, edad-, lugar en donde se lo depositaba y nombre del responsable del sepulcro. Incluía una columna para anotar cualquier cambio posterior (traslado o reducción, por ejemplo) y la fecha correspondiente. En Morteros este libro fue reemplazado por las "Fichas catastrales", a mediados del siglo Xx. Se los conserva en forma permanente en el Archivo General de la Municipalidad.

En Girona, el libro Registro de inhumaciones de cadáveres se lleva desde 1905 y en él se inscriben, cronológicamente, los enterramientos. Es de conservación permanente. ${ }^{29}$ Complementariamente, desde 1900 pero sólo hasta 1995 se llevó un libro Registro de exhumaciones y traslado de cadáveres, en el que se asentaban todas las exhumaciones que se realizaban en cada

28 "Taula d'avaluació documental". Codi: 431 DogC: 3604 Sèrie documental: Expedients d'autorització d'exhumació de cadàvers pel trasllat de sepultura o incineració sense la presència de la família, en http://cultura.gencat.cat/arxius/cnatdt/docs/431.doc. [Consulta 20 de febrero de 2011]. Esta serie está en revisión actualmente. (Información remitida vía electrónica por Lluís-Esteve Casellas i Serra).

29 "Taula d'avaluació documental". Codi: 435 DogC: 3604 Sèrie documental: Llibre registre d'inhumacions de cadàvers, en http://cultura.gencat.cat/arxius/cnatdt/docs/435.doc. [Consulta 20 de febrero de 2011] 
cementerio independientemente del motivo que la originara, el cual también es de conservación permanente. Desde 1977 se lleva conjuntamente con el de inhumaciones e incineraciones. ${ }^{30}$

\subsection{En relación con la renta municipal}

\section{3. a) Registro de propietarios de sepulturas}

También llamado "Padrón de contribuyentes", es un documento en el que se registra fecha del asiento, nombre y apellido del responsable, designación catastral y tipo de sepultura (panteón, nicho, fosa); su función administrativa es ubicar al responsable de cada sepulcro, por tipo de construcción. El área Recursos Tributarios del municipio lo utiliza como base para cobrar la tasa administrativa anual correspondiente. Inicialmente se trataba de un libro pero en actualidad está en soporte digital (base de datos) y se puede acceder por nomenclatura catastral, por apellido y nombre del propietario o responsable, o por apellido y nombre de un difunto. Por su naturaleza, es un documento activo, que se actualiza en forma permanente. Al comienzo de cada año se imprime un ejemplar, que se conserva durante veinticinco años; después se elimina y se conservan como muestra, los registros de los años terminados en 0 y 5 .

La serie semejante, en cuanto a la información que registra y función que desempeña en Girona, es el "Padrón de la tasa por Servicio de conservación de cementerios". En la "Tabla de evaluación documental" correspondiente a esta serie se propone conservarlos durante quince años, ordenados alfabéticamente y después realizar un muestreo cronológico, reteniendo los padrones, ordenados por responsable del pago de la tasa, de los años terminados en 0 y 5 , hasta 1975 y de los años terminados en 1 y 6 a partir de 1981. Se han elegido esos años en función de la coincidencia con la fecha de realización del padrón de habitantes y de los censos de población. ${ }^{31}$

30 “Taula d'avaluació documental'. Codi: 437 DOGC: 3604 Sèrie documental: Llibre registre d'exhumacions i trasllats de cadàvers, en http://cultura.gencat.cat/arxius/cnatdt/docs/437. doc. [Consulta 20 de febrero de 2011]

31 Ibid., Codi: 211. DogC: 2685 Sèrie documental: Padró de la taxa pel servei de conservació de cementiris, en http://cultura.gencat.cat/arxius/cnatdt/docs/211.doc. [Consulta 20 de febrero de 2011]. 


\section{3.b) Registro de pagos y deudores - contribución que incide sobre cementerios}

Es un instrumento de control de lo percibido por el municipio en concepto de concesiones de fosas y nichos. Se trata de un documento en soporte digital, que se utiliza para verificar los pagos y realizar los reclamos en caso de mora. Incluye información sobre nomenclatura catastral, identificación del responsable, tarifa, fecha y número del comprobante de pago. Dada su naturaleza y características, se actualiza cada vez que se generan pagos y se utiliza en forma permanente en la oficina.

Por tratarse de documentos de control económico, no se ha analizado la serie similar del Ayuntamiento de Girona, existente en el servicio de recaudación.

\section{Valoración de los documentos de cementerios}

Identificados los documentos de cementerios producidos en Morteros y Girona, se estudiarán sus valores primarios y secundarios, puntualizando algunos criterios de valoración.

\section{Valor Primario}

\subsection{Componente $o$ aspecto administrativo}

Los documentos se producen con un fin administrativo específico, que corresponde a su valor primario. Así, en los documentos y series identificados, se puede advertir que:

$\mathrm{La}$ "Ordenanza general de cementerios" (Morteros), al igual que el "Reglamento de cementerios municipales" (Girona) tiene por finalidad fijar el régimen administrativo de los enterramientos y de las concesiones, así como las disposiciones para la inhumación, exhumación, cremación y traslado de cadáveres. Conserva este valor mientras dure su vigencia, es decir, hasta que sea derogada o modificada por un instrumento similar.

Los "Expedientes de construcciones de particulares en cementerios" (Morteros) y los "Expedientes de permisos de obras e instalaciones de elementos ornamentales en las sepulturas" (Girona) tienen valor administrativo mientras se mantiene la obra de que se trata por cuanto la información que contienen es necesaria para el municipio. 
Los "Expedientes de concesión de uso de parcelas" (Morteros) y los "Expedientes de gestión de derechos funerarios sobre sepulturas" (Girona) presentan valor administrativo mientras dura la concesión, ya que en ellos está registrado el procedimiento llevado a cabo.

Las "Constancias de arrendamiento de fosa y/o nicho" (Morteros) son útiles para identificar al responsable y conservan este valor durante el plazo de la concesión. Como se recordará, en Girona no existe una serie similar, por cuanto el trámite se realiza mediante el "Expediente de gestión de derechos funerarios sobre sepulturas".

Las "Fichas catastrales" (Morteros) así como la serie paralela en Girona, el libro Registro general de sepulturas y parcelas permiten identificar los sepulcros y los cadáveres enterrados en cada una de ellos; tienen valor administrativo mientras exista el panteón y haya cadáveres depositados en él.

El "Expediente o legajo de adquisición del inmueble" (Morteros) tiene valor administrativo mientras el municipio sea propietario del predio. Lo mismo ocurre en el Ayuntamiento de Girona.

Los "Legajos de obras en los cementerios" (Morteros) así como la serie "Construcción y mantenimiento de equipamientos municipales" (Girona) tienen este valor durante la ejecución de los trabajos y hasta que se cumplan los plazos de cumplimiento de obligaciones y garantías, tanto del municipio como del constructor.

Las “Autorizaciones de inhumación” (Morteros) y los "Expedientes de inhumación o incineración de cadáveres" (Girona) tienen valor administrativo mientras el cadáver esté sepultado en el lugar indicado en la autorización correspondiente.

Las "Autorizaciones de exhumación para traslado, para incineración o para reducción" (Morteros) y los "Expedientes de autorización de exhumación de cadáveres por traslado de sepultura o incineración sin la presencia de la familia" (Girona) tienen valor administrativo hasta que se ejecuta el traslado, la incineración o la reducción autorizada.

El "Registro de inhumaciones" (Morteros) y el libro Registro de inhumaciones de cadáveres (Girona) tienen largo valor administrativo por cuanto la información que contienen interesa al municipio mientras exista el cementerio. 
El "Registro de propietarios de sepulturas" (Morteros) y el "Padrón de la tasa por servicio de conservación de cementerios" (Girona) tienen valor administrativo durante un año calendario, por cuanto se actualiza anualmente a los fines impositivos y, consecuentemente, concluye su valor primario.

\subsection{Componente $o$ aspecto legal}

Si bien de manera general todos los documentos se sustentan en la ley, tienen esta faceta de valor primario aquellos que respaldan derechos $\mathrm{u}$ obligaciones concretos del ciudadano o, en el caso que nos ocupa, del municipio o ayuntamiento. En muchos casos, coincide con el administrativo pero algunos presentan ciertas particularidades.

$\mathrm{Si}$ se retoman las series identificadas en el acápite anterior, se observa que:

La "Ordenanza general de cementerios" (Morteros), y el "Reglamento de cementerios municipales" (Girona) mantienen valor legal después de haber sido derogados o modificados, como antecedente o como respaldo de derechos adquiridos.

Las "Constancias de arrendamiento de fosa y/o nicho" (Morteros) son, en muchos casos, el único documento que prueba dónde está enterrado un cadáver. En algunos juicios relacionados con desaparecidos en los períodos de terrorismo de Estado, la información contenida en esta serie permitió identificar a cadáveres sepultados como "NN" así como a los responsables o encubridores de estos crímenes, por cuanto estos cuerpos no fueron enterrados en sepulcros particulares, sino arrendados circunstancialmente a la municipalidad.

\section{Valor secundario}

El valor secundario de los documentos de cementerio radica en que son una fuente fundamental para estudios genealógicos, antropológicos, históricos, de identidad, estadísticos, sanitarios, de género, arquitectónicos, sociológicos, de vida cotidiana, de ideología, religiosos o de derechos humanos. Se analizan algunos de ellos:

\subsection{Estudios genealógicos}

Para encontrar los antecedentes genealógicos es esencial contar con las 
actas de los registros civiles de nacimiento, matrimonio y defunción, en especial estas últimas, porque los datos que contienen permiten remontar los ascendientes de una persona. Cuando no están los documentos en los registros civiles, por alguna causa fortuita, o cuando se investigan períodos anteriores a su existencia, el investigador debe recurrir a archivos parroquiales en cuyo caso las actas de bautismo, de matrimonio y de defunción son fundamentales. ${ }^{32}$

Los "Registros de inhumaciones", "Fichas catastrales", "Autorizaciones deinhumacióny de exhumación”, además de informar dónde están sepultados los miembros de una familia y la fecha de enterramiento, aportan datos para comenzar la búsqueda en los registros civiles. Complementariamente, los "Expedientes de construcciones de particulares en cementerios" proporcionan información acerca de la situación económica de familias o corporaciones, como cofradías religiosas o sociedades de socorros mutuos, a las cuales pertenecía el individuo.

\subsection{Estudios antropológicos}

Para la antropología son de suma utilidad los documentos de muertos y de cementerios; dado que su campo de investigación incluye las creencias, el arte, la moral, el derecho, las costumbres y hábitos adquiridos por el hombre como miembro de una sociedad. Las informaciones de los "Expedientes de construcciones de particulares en cementerios", porejemplo, permiten conocer los profesionales que trabajaron en el lugar, la situación socioeconómica de una familia determinada y hasta inferir la visión de la muerte del profesional y de los propietarios de los mausoleos, de acuerdo con la estructura que eligen y con los elementos con que los adornan, como vitraux, altares o epitafios. En este caso se cruza con los estudios arquitectónicos.

Del mismo modo, las "Fichas catastrales" brindan información acerca de lo que ocurrió en cada parcela a lo largo del tiempo, y de ellas se pueden deducir comportamientos sociales respecto de los muertos, tales como formas de enterrar, posibilidad de reducir y de incinerar al difunto, entre otros aspectos del devenir diacrónico de ese espacio.

En este campo son especialmente necesarios los documentos de

32 Tejerina Carreras, "Introducción a los estudios genealógicos”, pp.15-16 y 30-35. 
cementerio para los referidos a antropología forense y todos los relacionados con la recuperación de la memoria de períodos dictatoriales que permiten trabajar sobre derechos humanos.

\subsection{Estudios históricos-culturales}

En lo que se refiere a la historia, los documentos de cementerio son fuente para un amplio espectro temático, más allá de aquellos esencialmente vinculados con la muerte. Así entre muchos otros, el análisis de la legislación permite conocer los conflictos entre la Iglesia y el Estado, la evolución de las políticas sanitarias — que permiten constatar enfermedades y epidemias- y hasta del uso de la tierra.

Del mismo modo, es posible investigar acerca de los modelos arquitectónicos a través del tiempo, el patrimonio cultural de un lugar mediante diferentes manifestaciones, según los diversos credos.

\section{Algunos criterios de conservación y de eliminación}

No existe un criterio ideal o exclusivo que pueda aplicarse en todos los casos y en todos los archivos, para decidir la conservación o eliminación de una serie. Por eso, es necesario respetar los principios y premisas generales de la teoría archivística y utilizar el o los criterios más convenientes según el fin perseguido.

En general se deben conservar los documentos que pueden ser útiles al futuro usuario, porque contienen datos sobre la organización, su estructura y funcionamiento o proporcionan testimonios sobre personas, cosas o hechos y que, por ende, formarán parte del patrimonio documental local y eliminar aquellos cuyo contenido informativo no trasciende el valor primario, es repetitivo o puede encontrarse en otro documento.

Si se trata de documentos recapitulativos, Lluís-Esteve Casellas i Serra, observa que "la consideración de una serie como recapitulativa de otra únicamente es válida si contiene la información esencial de esta de forma íntegra y si, además, ofrece las mismas garantías de autenticidad y de validez jurídica". ${ }^{33}$

Respecto de series relacionadas, debe estudiarse la interdependencia de

33 Casellas i Serra, "La evaluación y selección de la documentación económica”, p. 13. 
la información contenida, es decir, verificar en qué medida la información de una serie es comprensible sin el conocimiento y la vinculación a otra serie, en tanto que la una y la otra corresponden a distintas actividades administrativas de una misma función. ${ }^{34}$

La Norma ISO 15489-1 recomienda identificar los intereses legítimos y exigibles que los ciudadanos pueden tener en relación con la conservación de los documentos durante un período de tiempo superior al requerido por el propio municipio; identificar y evaluar los beneficios legales, financieros, políticos, sociales y de cualquier otro tipo que se deriven de la conservación de los documentos al servicio de la investigación y de la sociedad en su conjunto; y cumplir, de existir, las disposiciones reglamentarias de la autoridad archivística competente. ${ }^{35}$

Sobre la base de los criterios establecidos por distintos autores, ${ }^{36}$ se propone tener en cuenta los siguientes criterios que, a modo de ejemplo, se aplicarán sobre los documentos de cementerio de Morteros:

Deben ser conservadas las series documentales que permiten conocer los orígenes del organismo, su organización, la evolución de sus estructuras y sus políticas, funciones, programas, disposiciones y actividades, esto es, conocer cómo actuaba y cómo interpretaba la realidad social (ej: la "Ordenanza general de cementerios"); aquellas que contienen datos significativos sobre acontecimientos, lugares, instituciones, personas, movimientos y tendencias de la historia política, económica y social (ej: las "Constancias de arrendamiento de fosas y/o de nichos", y las "Fichas catastrales"); las que contienen información necesaria para la protección de derechos del municipio, de personas o de instituciones (ej: los "Expedientes de concesión de uso de parcelas"); las que documentan derechos y obligaciones del municipio y de los individuos (ej: los "Expedientes o legajos de adquisición de inmueble”); las que contienen información acerca de la evolución de las artes, las ciencias y las técnicas (ej: los "Expedientes de construcciones de particulares en cementerios" y los "Legajos de obras municipales en los cementerios") y aquellas que completan la información de

\section{Idem.}

35 Norma Iso 15489-1:2001, apartado 9.2, p.17.

36 Cf. Cermeno Martorell y Rivas Palá, Valorar y seleccionar, Couture, "Las Tablas de Plazos de Conservación; Casellas i Serra, "La evaluación y selección de la documentación". 
otros fondos o series documentales (ej: las "Autorizaciones: de inhumación $y$ de exhumación para traslado, para incineración y para reducción”, que completan la información de las "Fichas catastrales" a las que se adjuntan). Además, las series que contienen información necesaria para análisis estadísticos y de historia cuantitativa (ej: el "Registro de inhumaciones"), las que proporcionan información y pruebas acerca de la interacción entre la organización y los ciudadanos (ej: el "Registro de propietarios de sepulturas",) así como las que contribuyen a la elaboración de la memoria de la organización.

Además de tener en cuenta estos criterios, en todos los casos es fundamental la conservación del contexto de producción del documento, que permitirá a futuros usuarios juzgar su autenticidad y fiabilidad, incluso en sistemas de gestión de documentos cerrados o que hayan sufrido importantes cambios.

Pueden eliminarse las copias, cuando los documentos originales están localizados y en buen estado de conservación, una vez concluido el valor primario (ej: las "Autorizaciones de inhumación" y las "Autorizaciones de exhumación para traslado, para incineración o para reducción”); y los documentos cuya información se encuentra recapitulada en otros documentos (ej: los "Expedientes de gestión de derechos funerarios sobre sepulturas", del Ayuntamiento de Girona). 


\section{CuAdro Comparativo DE los DOCUMENTOS IDENTIFICADOS Y SUS PLAZOS DE CONSERVACIÓN}

\begin{tabular}{|c|c|c|c|c|}
\hline \multicolumn{2}{|c|}{ Morteros } & \multicolumn{2}{|c|}{ Girona } & \multirow[t]{2}{*}{ Observaciones } \\
\hline Serie & $\begin{array}{c}\text { Plazo de } \\
\text { conservación }\end{array}$ & Serie & $\begin{array}{c}\text { Plazo de } \\
\text { conservación }\end{array}$ & \\
\hline $\begin{array}{l}\text { Ordenanza } \\
\text { General de } \\
\text { Cementerios. }\end{array}$ & Permanente & $\begin{array}{l}\text { Reglamento } \\
\text { de } \\
\text { Cementerios } \\
\text { Municipales }\end{array}$ & Permanente & \\
\hline $\begin{array}{l}\text { Expedientes de } \\
\text { construcciones } \\
\text { de particulares } \\
\text { en } \\
\text { cementerios }\end{array}$ & Permanente & $\begin{array}{l}\text { Expedientes } \\
\text { de permisos } \\
\text { de obras e } \\
\text { instalaciones } \\
\text { de elementos } \\
\text { ornamentales } \\
\text { en las } \\
\text { sepulturas }\end{array}$ & Permanente & $\begin{array}{l}\text { Si se trata de } \\
\text { nichos, se } \\
\text { eliminan a los } \\
\text { dos años. }\end{array}$ \\
\hline $\begin{array}{l}\text { Expedientes } \\
\text { de concesión } \\
\text { de uso de } \\
\text { parcelas }\end{array}$ & Permanente & $\begin{array}{l}\text { Expediente } \\
\text { de gestión } \\
\text { de derechos } \\
\text { funerarios } \\
\text { sobre } \\
\text { sepulturas }\end{array}$ & 4 años & \\
\hline $\begin{array}{l}\text { Constancia } \\
\text { de arrenda- } \\
\text { miento de fosa } \\
\text { y/o nicho }\end{array}$ & Permanente & & & \\
\hline $\begin{array}{l}\text { Fichas } \\
\text { catastrales }\end{array}$ & Permanente & $\begin{array}{l}\text { Libro Registro } \\
\text { General de } \\
\text { Sepulturas y } \\
\text { parcelas }\end{array}$ & Permanente & \\
\hline $\begin{array}{l}\text { Expediente } \\
\text { o legajo de } \\
\text { adquisición del } \\
\text { inmueble }\end{array}$ & Permanente & & & $\begin{array}{l}\text { No se analiza, } \\
\text { aunque existe, } \\
\text { en la unidad } \\
\text { de Patrimonio. }\end{array}$ \\
\hline $\begin{array}{l}\text { Legajo de } \\
\text { obras en los } \\
\text { cementerios }\end{array}$ & $\begin{array}{l}10 \text { años, se } \\
\text { depuran y } \\
\text { se conservan } \\
\text { permanente- } \\
\text { mente los } \\
\text { documentos } \\
\text { con valor } \\
\text { secundario. }\end{array}$ & $\begin{array}{l}\text { Construcción } \\
\text { y manteni- } \\
\text { miento de } \\
\text { equipamien- } \\
\text { tos munici- } \\
\text { pales. }\end{array}$ & & $\begin{array}{l}\text { No se analiza } \\
\text { por tener rela- } \\
\text { ción indirecta } \\
\text { con el tema } \\
\text { que se trata. }\end{array}$ \\
\hline
\end{tabular}




\begin{tabular}{|c|c|c|c|c|}
\hline \multicolumn{2}{|c|}{ Morteros } & \multicolumn{2}{|c|}{ Girona } & \multirow[t]{2}{*}{ Observaciones } \\
\hline Serie & $\begin{array}{c}\text { Plazo de } \\
\text { conservación }\end{array}$ & Serie & $\begin{array}{c}\text { Plazo de } \\
\text { conservación }\end{array}$ & \\
\hline $\begin{array}{l}\text { Autorizaciones } \\
\text { de inhumación }\end{array}$ & Permanente & $\begin{array}{l}\text { Expedientes } \\
\text { de } \\
\text { inhumación o } \\
\text { incineración } \\
\text { de cadáveres }\end{array}$ & 4 años & \\
\hline $\begin{array}{l}\text { * Autorizacio- } \\
\text { nes de exhu- } \\
\text { mación para } \\
\text { traslado } \\
\text { * Autorizacio- } \\
\text { nes de exhu- } \\
\text { mación para } \\
\text { incineración } \\
\text { * Autorizacio- } \\
\text { nes de exhu- } \\
\text { mación para } \\
\text { reducción }\end{array}$ & $\begin{array}{l}5 \text { años. } \\
\text { Conservación } \\
\text { permanente } \\
\text { de un } \\
\text { ejemplar en } \\
\text { la oficina del } \\
\text { cementerio }\end{array}$ & $\begin{array}{l}\text { Expedientes } \\
\text { de } \\
\text { autorización } \\
\text { de } \\
\text { exhumación } \\
\text { de cadáveres } \\
\text { por traslado } \\
\text { de sepultura } \\
\text { o incineración } \\
\text { sin la } \\
\text { presencia de } \\
\text { la familia }\end{array}$ & 5 años & \\
\hline $\begin{array}{l}\text { Registro de } \\
\text { inhumaciones }\end{array}$ & Permanente & $\begin{array}{l}\text { Libro } \\
\text { Registro de } \\
\text { inhumaciones } \\
\text { de cadáveres }\end{array}$ & Permanente & \\
\hline \multirow[t]{2}{*}{$\begin{array}{l}\text { Registro de } \\
\text { Propietarios de } \\
\text { sepulturas }\end{array}$} & $\begin{array}{l}25 \text { años. } \\
\text { Muestreo } 1 \\
\text { año de cada } \\
5 .\end{array}$ & $\begin{array}{l}\text { Padrón de } \\
\text { la tasa por } \\
\text { Servicio de } \\
\text { conservación } \\
\text { de } \\
\text { cementerios } \\
\end{array}$ & $\begin{array}{l}15 \text { años. } \\
\text { Muestreo } \\
1 \text { año de } \\
\text { cada } 5 .\end{array}$ & \\
\hline & & $\begin{array}{l}\text { Libro } \\
\text { Registro de } \\
\text { exhumaciones } \\
\text { y traslado de } \\
\text { cadáveres }\end{array}$ & Permanente & \\
\hline
\end{tabular}

Legajos, número 1, enero-marzo, 2014109 


\section{A modo de conclusión}

Se han identificado trece series documentales del área Cementerios de la Municipalidad de Morteros, once de las cuales, con pocas diferencias de contenido y a veces de denominación, se producen también en Girona. Esto es así porque las facultades y responsabilidades del Estado municipal ante la muerte de sus ciudadanos son las mismas, independientemente del país y del régimen administrativo. Del mismo modo, funciones idénticas producen documentos iguales o con pocos cambios, cuando el procedimiento administrativo que les dio origen exige algún trámite extra o, por el contrario, requiere menos pasos.

De las series identificadas, la mayoría son de conservación permanente y de las que se eliminan, la información se encuentra en otro documento recapitulativo. Esto significa que los documentos relacionados con la muerte y el cementerio son valiosos, tanto desde el punto de vista administrativo y legal, como informativo e histórico.

La utilización de criterios de conservación y de eliminación similares permite la conservación definitiva de las mismas series. Es conveniente, entonces, trabajar en forma interdisciplinaria e interinstitucional, aprovechando las sinergias de trabajo entre profesionales, así como las experiencias individuales para lograr la creación de modelos que puedan adaptarse a las realidades locales y homologar criterios entre organismos paralelos, no solo en la misma región y país, sino a nivel internacional. La normalización en este sentido beneficiará también al usuario, por cuanto le permitirá conocer anticipadamente qué documentos se han conservado y cuáles se han eliminado, cualquiera sea el Municipio de que se trate.

\section{Bibliografía y fuentes}

\section{Fuentes}

ACM Archivo Central de la Municipalidad de Morteros.

AGM Archivo General de la ciudad de Morteros.

AHPC Archivo Histórico de la Provincia de Córdoba.

Constitución de la Nación Argentina.

Constitución de la Provincia de Córdoba. 
CNATD Comissió Nacional d'Avaluació i Tria de la Documentació Norma ISO 15489-1:2001, Información y documentación. Gestión de documentos, Parte 1: Generalidades.

\section{Bibliografía}

Brel Cachón, María Pilar, "La construcción de cementerios y la salud pública a lo largo del siglo XIX”, en Studia Zamorensia, núm. 5, 1999, pp.155-196.

Cardona Saldarriaga, Álvaro y Sierra Varela, Raquel, "Salud pública y prohibición de enterramientos en las iglesias en la Nueva Granada a finales del siglo XVIII", en Espacio Abierto, Revista Gerencia y Políticas de Salud, Bogotá (Colombia), 7 (14), enero-junio de 2008, pp. 54-72.

Casellas i Serra, Lluís-Esteve, "La evaluación y selección de la documentación económica del municipio: la experiencia desde Catalunya”, en III Jornadas de archivos municipales de Cantabria: Medio Cudeyo, 26 y 27 de abril de 2001, Santander, Consejería de Cultura, Turismo y Deporte, Asociación para la Defensa del Patrimonio Bibliográfico y documental de Cantabria, 2001, pp. 123-163.

Cermeno Martorell, Lluís y Rivas Palá, Elena, Valorar y seleccionar documentos. Qué es y cómo se hace. Colección Archivos Siglo XXI -20. Gijón, Trea, 2010. Couture, Carol, "Las Tablas de Plazos de Conservación: Fundamentos teóricos y estado de las prácticas", en Janus 1998.1 - Lligall 12 - Revista Catalana d'Arxivística, Associació d'Arxivers de Catalunya, Barcelona, 1997, pp. 164-18.

Fenoglio, Norma Catalina, "Valor de los archivos de catastro. Municipalidad de Morteros, Provincia de Córdoba, Argentina", en COMMA, 2009.1: Architectural Records, Revista del Consejo Internacional de Archivos, ICA, Paris. 2010, pp.91-97.

,Evaluación de los documentos de las administracionespúblicas municipales - estudio de casos en Brasil y Argentina, presentado en el $16^{\circ}$ Congreso Internacional de Archivos, Kuala Lumpur, mesa 113: La evaluación de los documentos en América Latina. Situación y perspectivas a inicios del siglo XXI, ICA, 2008, inédito.

Gaido Andrea C. y Carranza, Rosana M., El cementerio de Villa María (18671910). Trabajo final de licenciatura en historia, FFyH, UCC, año 2008. Inédito. 
Martínez de Sánchez, Ana María, Álvarez Rodríguez, Mariela y Fenoglio, Norma C, "Entre memoria y olvido. Los archivos de cementerios generales", en Actas del X Encuentro Iberoamericano de Valoración y Gestión de Cementerios Patrimoniales, Medellín (Colombia), publicado en CD.

Nistal, Mikel, Legislación funeraria y cementerial española: Una visión espacial, en Lurralde, núm. 19, Instituto Geográfico Vasco, 1996. pp. 29-53.

Solari Teresita, Laura Echenique y Pablo Gruttadauría, "Cementerios públicos. Legislación nacional”, en Ghirardi, Juan Carlos (dir.) y otros, Régimen Juridico de los sepulcros, Editorial de la Universidad Católica de Córdoba, 2009, pp.197-215.

Solari Teresita, Laura Echenique y Lucas Di Pasquantonio, "Cementerios privados”, en Juan Carlos Ghirardi (dir.), Régimen jurídico de los sepulcros, Córdoba, Editorial de la Universidad Católica de Córdoba, 2009, pp.217233.

Tejerina Carreras, Ignacio. "Introducción a los estudios genealógicos", en Cuadernos de Historia, núm. 8, Junta Provincial de Historia de Córdoba, 1988.

Valls i Rovira, Francesc. La producció documental dels cementeris de Barcelona. Tipologies documentals. Trabajo final del V Mestratge d'araxívistica. Gestió dels documents $\mathrm{i}$ dels arxius, Universitat Autònoma de Barcelona, setiembre 2003, 2 volúmenes, inédito.

Vinti Ángela, Teresita Solari, Stella Maris Romero y otros, "Sepelios y sepulcros en la Provincia de Córdoba", en Juan Carlos Ghirardi (dir.), Régimen jurídico de los sepulcros, Córdoba, Editorial de la Universidad Católica de Córdoba, 2009, pp.341-425.

\section{Sitios web}

http://cultura.gencat.cat/arxius/cnatdt/docs/ http://www.girona.cat/ajuntament/ordenances/sanitat/servfunerais.html http://www.girona.cat/ajuntament/ordenances/sanitat/cementiris.html (D 